Special article

\title{
Enhancing plant diversity and mitigating BVOC emissions of urban green spaces through the introduction of ornamental tree species
}

\author{
Yuan Ren ${ }^{\mathrm{a}}$, Ying Ge $\mathrm{a}^{\mathrm{a}}$, Danping $\mathrm{Ma}^{\mathrm{b}}$, Xilu Song ${ }^{\mathrm{c}}$, Yan Shi ${ }^{\mathrm{d}}$, Kaixuan Pan ${ }^{\mathrm{a}}$, Zelong $\mathrm{Qu}^{\mathrm{a}}$, Peipei Guo ${ }^{\mathrm{e}}$, \\ Wenjuan Han ${ }^{\mathrm{a}}$, Jie Chang, \\ a College of Life Sciences, Zhejiang University, Hangzhou 310058, PR China \\ b Engineering Experimental Training Center, Zhejiang University of Water Resources and Electric Power, Hangzhou 310018, PR China \\ c Capital Construction Department, Shandong University of Science and Technology, Qingdao 266590, PR China \\ d School of Landscape Architecture, Zhejiang A \& F University, Lin'an 311300, PR China \\ e Research Center for Eco-Environmental Sciences, Chinese Academy of Sciences, Beijing 100085, PR China
}

\section{A R T I C L E I N F O}

\section{Keywords:}

Ecosystem services

Isoprene

Ozone

Urban greening

Urban planning

\begin{abstract}
A B S T R A C T
Promoting the plant diversity of urban green spaces is crucial to increase ecosystem services in urban areas. While introducing ornamental plants can enhance the biodiversity of green spaces it risks environmental impacts such as increasing emissions of biogenic volatile organic compounds (BVOCs) that are harmful to air quality and human health. The present study, taking Qingdao City as a case study, evaluated the plant diversity and BVOC emissions of urban green spaces and tried to find out a solution to increase biodiversity while reducing BVOC emissions. Results showed that: (1) the species diversity and phylogenetic diversity of trees in urban green spaces were $22 \%$ and $16 \%$ lower than rural forest of this region; (2) urban areas had higher BVOC emission intensity $\left(2.6 \mathrm{~g} \mathrm{C} \mathrm{m}^{-2} \mathrm{yr}^{-1}\right)$ than their rural surroundings $\left(2.1 \mathrm{~g} \mathrm{C} \mathrm{m}^{-2} \mathrm{yr}^{-1}\right)$; (3) introducing the selected 11 tree species will increase $15 \%$ and $11 \%$ of species diversity and phylogenetic diversity, respectively; and (4) the BVOC emissions from green spaces will more than triple by 2050, but a moderate introduction of the selected lowemitting trees species could reduce $34 \%$ of these emissions. The scheme of introducing low-emitting ornamental species leads to a win-win situation and also has implications for the sustainable green space management of other cities.
\end{abstract}

\section{Introduction}

Urbanization is accelerating worldwide (Ramalho and Hobbs, 2012; Seto et al., 2012). The rapid urban transition and associated land use change drives habitat loss, threatens biodiversity in urban areas (Kowarik, 2011; Palliwoda et al., 2017). As a way of compensation, urban green spaces (exclude ruminant vegetation) are purported to preserve biodiversity and provide a wide range of ecosystem services that are critical for human well-being (Goddard et al., 2010; Pataki et al., 2011; Wolch et al., 2014). Plant diversity and species composition play crucial roles in the functioning of urban ecosystems and the sustainable supply of ecosystem services (Zhang and Jim, 2014). For the purpose of improving human well-being in cities, there is an urgent need to understand, assess and optimize the plant diversity and species composition of urban green spaces.

Ornamental plant species are frequently introduced to green spaces to improve plant diversity and cultural services (e.g. aesthetic, recreation, educational and inspirational) of urban areas (Niinemets and
Peñuelas, 2008; Noe et al., 2008). Despite concerns about the ecological risks attributed to introduced species, such as the exacerbation of biological invasion, displacement of native species, and biotic homogenization (Kowarik, 2011; Qian et al., 2016), the process of species introduction in cities never slows down (Niinemets and Peñuelas, 2008). On the one hand, the introduction of ornamental plant species can enhance species diversity directly; on the other hand, the evolutionary distances of introduced ornamental species often differ greatly from the local ones, and thus may increase the phylogenetic diversity of green spaces significantly.

Another important impact of the introduction of ornamental tree species is the changes in emissions of biogenic volatile organic compounds (BVOCs). On a global scale, the source strengths of BVOCs far exceed those of anthropogenic VOCs (AVOCs) (Guenther et al., 2012). BVOCs are essential for plants to cope with various environmental stresses (Peñuelas and Staudt, 2010; Mentel et al., 2013). However, BVOCs emitted by urban trees, together with AVOCs from human activities, are believed to play critical roles in the formation of

\footnotetext{
* Corresponding author at: Department of Biological Science, College of Life Sciences, Zhejiang University, 866 Yuhangtang Road, Hangzhou 310058, PR China.

E-mail address: jchang@zju.edu.cn (J. Chang).
} 
tropospheric ozone and secondary organic aerosols, which have negative effects on air quality and human health in urban areas (Mueller and Mallard, 2011; Calfapietra et al., 2013; Harrison et al., 2013). Thus, from the perspective of improving human well-being, increases in BVOC emissions should be avoided when introducing ornamental tree species to cities (Noe et al., 2008; Tiwary and Kumar, 2014).

BVOC emissions are highly species-specific (Tani and Kawawata, 2008; Aydin et al., 2014), making it possible to mitigate emissions in urban areas by optimizing species composition in green spaces (Simpson and McPherson, 2011; Ren et al., 2014). In many temperate cities of China, urban green spaces are dominated by strong BVOC emitters from the genera Sophora, Platanus, Populus, and Salix (Ghirardo et al., 2016; Zhang et al., 2016), while many ornamental tree species origin from the subtropical zone have relatively lower BVOC emission potentials (Chang et al., 2012; Ren et al., 2014). If these low-emitting ornamental trees are introduced to green spaces of temperate cities, a win-win situation (i.e. reducing BVOC emissions while improving biodiversity) can be achieved.

Numerous efforts have been made worldwide to study the plant diversity of urban green spaces (Knapp et al., 2008; Goddard et al., 2010; Nielsen et al., 2014; Zhang and Jim, 2014). Urban green spaces are found to be locations of low plant diversity and are dominated by non-native species (Alvey, 2006). Several studies also focus on BVOC emissions from urban areas (Chang et al., 2012; Calfapietra et al., 2013; Ghirardo et al., 2016) and reveal that green spaces can emit considerable amount of BVOCs (Chang et al., 2012; Guo et al., 2013). All these previous studies have provided insights into the different aspects of urban green spaces. Nevertheless, plant diversity and BVOC emissions are seldom discussed together. In particular, no previous studies focused on enhancing plant diversity while reducing BVOC emissions through optimizing the species composition of urban green spaces.

In this study, we took Qingdao City, as a case study. Through an urban vegetation survey, we calculated the plant diversity of urban green spaces; using a BVOC estimation model based on vegetation, meteorological and land use data, we estimated BVOC emissions from green spaces in Qingdao. We further discussed the potentials of introducing ornamental tree species to reduce BVOC emissions and to improve the plant diversity of green spaces in Qingdao City. The findings could inform management decisions for urban greening of cities in temperate zones, and compact cities elsewhere facing similar challenges to enhance biodiversity and to control urban BVOC emissions.

\section{Material and methods}

\subsection{Study area}

Qingdao City $\left(35^{\circ} 35^{\prime}-37^{\circ} 09^{\prime} \mathrm{N}, 119^{\circ} 30^{\prime}-121^{\circ} 00^{\prime} \mathrm{E}\right)$ is located on the southwestern coast of Shandong Peninsula, bordering on the Yellow Sea in the east and contiguous to the mainland in the west with a land area of $11,282 \mathrm{~km}^{2}$ (NBSC, 2015). It is one of the largest coastal cities in China with a population of about 7.8 million (NBSC, 2015). Under the impact of ocean currents and the southeast monsoon, this region is characterized by a temperate monsoon climate and also has characteristics of a maritime climate, with an annual average temperature of $12.7^{\circ} \mathrm{C}$ and annual precipitation of around $660 \mathrm{~mm}$. Qingdao has been undergoing rapid urbanization, and its built-up area increased from $72 \mathrm{~km}^{2}$ in $1980-491 \mathrm{~km}^{2}$ in 2014 (QBS, 2015). Urban green spaces expanded even faster, increasing from 749 ha in $1980-21,934$ ha in 2014 (QBS, 2015).

\subsection{Investigation for urban green spaces}

We conducted an urban vegetation survey in the years 2013 and 2015 (Table 1; Table A.1). The survey encompassed six urban districts (Shinan, Shibei, Licang, Laoshan, Chengyang and Huangdao) which form the bulk of the built-up areas of Qingdao. Urban green spaces were
Table 1

The growth form, relative abundance (RA), relative frequency (RF), relative dominance (RD), and important value (IV) of 20 primary tree species in green spaces of Qingdao.

\begin{tabular}{|c|c|c|c|c|c|}
\hline Tree species & $\begin{array}{l}\text { Growth } \\
\text { form }^{\mathrm{a}}\end{array}$ & RA (\%) & RF (\%) & $\mathrm{RD}^{\mathrm{b}}(\%)$ & IV (\%) \\
\hline Platanus acerifolia & $\mathrm{dbt}$ & 18.2 & 21.5 & 29.2 & 68.9 \\
\hline Pinus thunbergii & ent & 9.7 & 7.7 & 7.1 & 24.5 \\
\hline Cedrus deodara & ent & 8.4 & 10.8 & 15.0 & 34.2 \\
\hline Robinia pseudoacacia & $\mathrm{dbt}$ & 6.0 & 6.90 & 6.9 & 19.8 \\
\hline Sophora japonica & $\mathrm{dbt}$ & 5.3 & 7.2 & 6.6 & 19.1 \\
\hline Ginkgo biloba & $\mathrm{dbt}$ & 4.0 & 7.9 & 2.2 & 14.1 \\
\hline Albizia julibrissin & $\mathrm{dbt}$ & 3.7 & 4.7 & 3.2 & 11.6 \\
\hline Fraxinus chinensis & $\mathrm{dbt}$ & 3.2 & 2.7 & 3.7 & 9.6 \\
\hline Cerasus yedoensis & $\mathrm{dbt}$ & 3.0 & 2.4 & 1.2 & 6.6 \\
\hline Lagerstroemia indica & $\mathrm{dbt}$ & 2.8 & 2.5 & 0.3 & 5.6 \\
\hline Populus tomentosa & $\mathrm{dbt}$ & 2.6 & 3.6 & 5.0 & 11.2 \\
\hline $\begin{array}{c}\text { Prunus cerasifera } \mathrm{f} . \\
\text { atropurpurea }\end{array}$ & $\mathrm{dbt}$ & 2.3 & 1.8 & 0.3 & 4.4 \\
\hline Yulania denudata & $\mathrm{dbt}$ & 2.1 & 1.8 & 0.5 & 4.4 \\
\hline Sabina chinensis 'Kaizuca' & ent & 1.9 & 2.1 & 0.9 & 4.9 \\
\hline Acer pictum ssp. Mono & $\mathrm{dbt}$ & 1.8 & 1.2 & 1.0 & 4.0 \\
\hline Melia azedarach & $\mathrm{dbt}$ & 1.5 & 0.8 & 0.4 & 2.7 \\
\hline Amygdalus persica f. duplex & $\mathrm{dbt}$ & 1.3 & 1.8 & 0.2 & 3.3 \\
\hline Liriodendron chinense & $\mathrm{dbt}$ & 1.2 & 1.4 & 0.8 & 3.4 \\
\hline Magnolia grandiflora & ebt & 1.0 & 1.1 & 0.5 & 2.6 \\
\hline Celtis sinensis & $\mathrm{dbt}$ & 1.0 & 0.7 & 1.4 & 3.1 \\
\hline
\end{tabular}

${ }^{a}$ Growth form: dbt, deciduous broadleaved tree; ebt, evergreen broad-leaved tree; ent, evergreen needle-leaved tree.

b relative dominance was calculated as the ratio of basal area at breast height for each species to the total basal area.

divided into four types: street green space, park green space, residential green space, and affiliated green space (in schools and institutional units). A stratified random selection method (Nowak et al., 2008) was applied, and a total of 198 plots $\left(400 \mathrm{~m}^{2}\right)$ were investigated. Within each plot, all trees $(\mathrm{DBH}>2.5 \mathrm{~cm})$ were identified and measured for diameter at breast height (DBH) and tree height.

\subsection{Introduction trial of ornamental tree species from subtropical regions}

The introduction trial was conducted on the Qingdao campus of the Shandong University of Science and Technology. From 2003-2010, we introduced 13 ornamental tree species with relatively low BVOC emissions (Table A.2; Table A.3) to the campus from the southern provinces of Jiangsu and Zhejiang. This included 6 evergreen broadleaved tree species, 6 deciduous broad-leaved species, and 1 evergreen coniferous species (Table 2). Most of these tree species have been widely used in the urban greening of southern China but were not found in the vegetation survey of Qingdao. Six of these tree species are listed as national key protected wild plants of China (Table 2). Tree health conditions and the annual changes in DBH were regularly detected after they were transplanted to the campus. To make a comparison, many other ordinary tree species that were widely used in the urban green spaces of Qingdao were also transplanted to the campus as ornamental trees.

\subsection{Biodiversity calculation and phylogenetic tree reconstruction}

Some numerical indices developed in vegetation ecology and commonly applied in urban-forestry research have been adopted in this study. We considered both the species diversity and phylogenetic diversity of urban trees. Species diversity was represented by the Gleason index $(D)$ calculated by (Gleason, 1922):

$D=S / \ln A$

where $S$ was the total number of species, $A$ was the area of the community. The attribute $D$ was analyzed with reference to all of Qingdao and by tree-habitats (i.e. plots). 
Table 2

Characteristics of the 13 introduced tree species.

\begin{tabular}{|c|c|c|c|c|c|}
\hline Tree species & Growth form ${ }^{c}$ & Year of introduction & No. of trees & Survival rate (\%) & DBH increment $\left(\mathrm{cm} \mathrm{yr}^{-1}\right)$ \\
\hline Cinnamomum camphora ${ }^{\mathrm{a}, \mathrm{b}}$ & ebt & 2003 & 80 & 90 & 0.51 \\
\hline Ilex rubra ${ }^{\mathrm{a}}$ & ebt & 2008 & 240 & 96 & 0.87 \\
\hline Ilex latifolia ${ }^{\mathrm{a}}$ & ebt & 2009 & 18 & 94 & 0.82 \\
\hline Manglietia insignis ${ }^{\mathrm{a}}$ & ebt & 2009 & 10 & 90 & 0.65 \\
\hline Michelia chapensis ${ }^{\mathrm{a}, \mathrm{b}}$ & ebt & 2006 & 25 & 96 & 0.66 \\
\hline Michelia maudiae $^{\mathrm{a}}$ & ebt & 2007 & 30 & 93 & 0.59 \\
\hline Camptotheca acuminata ${ }^{\mathrm{a}, \mathrm{b}}$ & $\mathrm{dbt}$ & 2007 & 20 & 95 & 0.56 \\
\hline Cercidiphyllum japonicum ${ }^{\mathrm{b}}$ & $\mathrm{dbt}$ & 2010 & 20 & 25 & 0.35 \\
\hline Eucommia ulmoides ${ }^{\mathrm{a}}$ & $\mathrm{dbt}$ & 2005 & 28 & 95 & 0.52 \\
\hline Houpoea officinalis ${ }^{\mathrm{a}, \mathrm{b}}$ & $\mathrm{dbt}$ & 2006 & 100 & 98 & 0.56 \\
\hline Triadica sebifera ${ }^{\mathrm{a}}$ & $\mathrm{dbt}$ & 2005 & 30 & 93 & 0.65 \\
\hline Nyssa sinensis & $\mathrm{dbt}$ & 2010 & 30 & 40 & 0.48 \\
\hline Taxus wallichiana var. maire $\mathrm{i}^{\mathrm{a}, \mathrm{b}}$ & ent & 2009 & 40 & 95 & 0.62 \\
\hline
\end{tabular}

${ }^{a}$ Tree species that we recommended to be promoted in the urban greening of Qingdao.

b species in the list of national key protected wild plants.

c growth form: dbt, deciduous broad-leaved tree; ebt, evergreen broad-leaved tree; ent, evergreen needle-leaved tree.

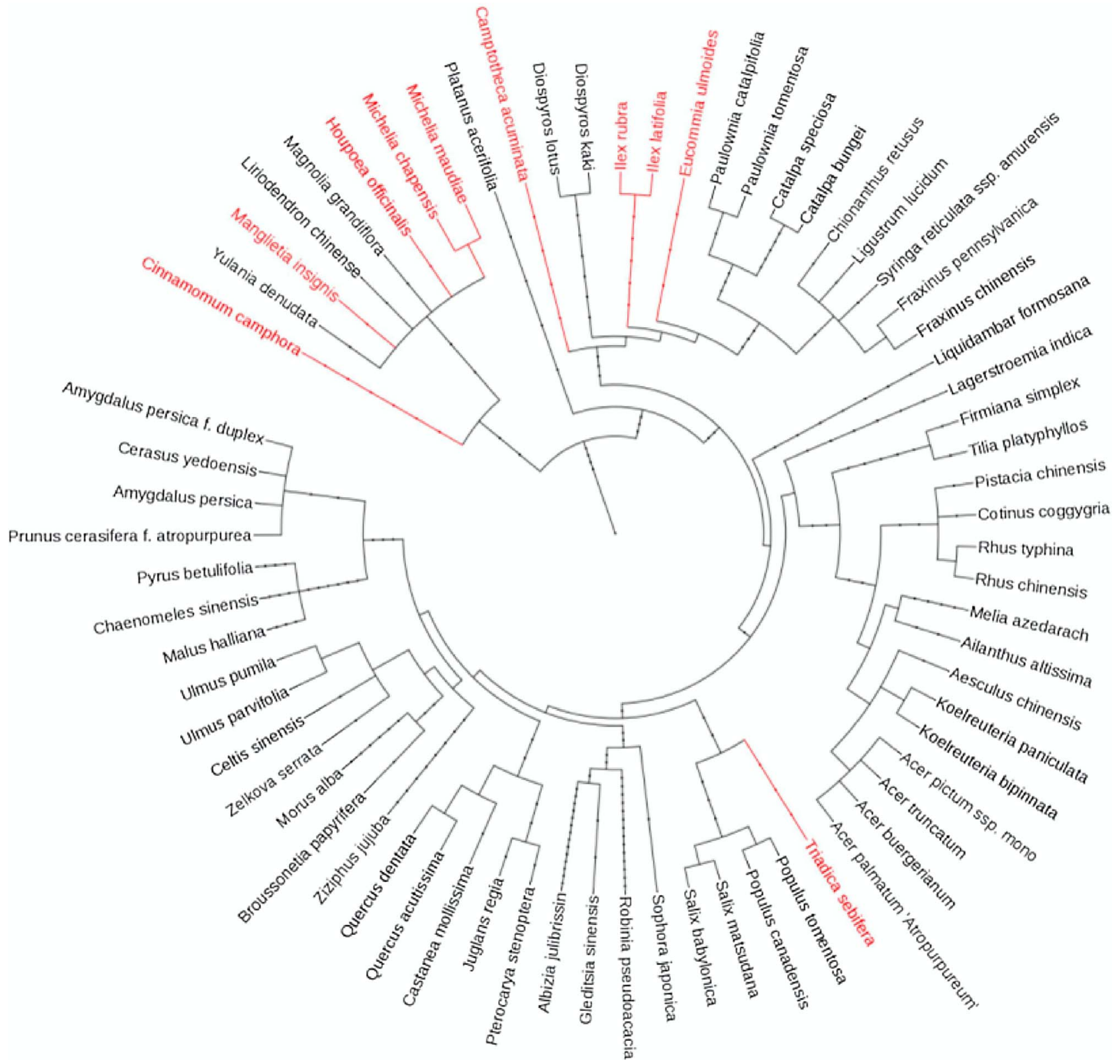

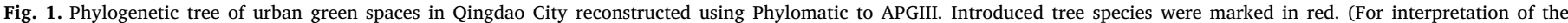
references to colour in this figure legend, the reader is referred to the web version of this article.) 
We used the online software Phylomatic (Webb and Donoghue, 2005) to reconstruct the phylogenetic tree, which based on Angiosperm Phylogeny Group's system (APG III, 2009). We used the BLADJ algorithm in Phylocom 4.1 (Webb et al., 2008) and estimates of angiosperm node ages were taken from Wikstrom et al. (2001) to assign branch lengths to the phylogenetic tree. The phylogenetic tree (Fig. 1) was presented using the web tool iTOL (Letunic and Bork, 2006).

We used Faith's phylogenetic diversity (PD) metric (Faith, 1992) to quantify the phylogenetic diversity. PD was defined as the minimum total length of all the phylogenetic branches required to span a given set of taxa on the phylogenetic tree (Faith, 1992). We used the PD algorithm in Phylocom 4.1 (Webb et al., 2008) to estimate the phylogenetic diversity of urban green spaces and rural forests in Qingdao. The species list of rural forests in Qingdao was obtained from Cao (2015).

\subsection{BVOC estimation}

BVOCs were divided into three groups: isoprene, monoterpenes, and other VOCs (OVOCs). Isoprene emission was treated as light-dependent (synthesis emission); OVOCs were treated as light-independent (pool emissions); while monoterpenes were assumed to have both synthesis emissions and pool emissions (Ghirardo et al., 2010; Oderbolz et al., 2013; Ghirardo et al., 2016). The basic BVOCs algorithms were derived from Guenther (Guenther et al., 1995; Guenther, 1997) and were revised based on other studies (Staudt et al., 2000; Heald et al., 2009). The synthesis isoprene $\left(E_{I S P}\right)$ and monoterpene $\left(E_{M N S}\right)$ emissions were quantified as:

$E_{I S P}=\varepsilon_{I S P} D \gamma_{T} \gamma_{P} \gamma_{S} \gamma_{C}$

$E_{M N S}=\varepsilon_{M N S} D \gamma_{T} \gamma_{P} \gamma_{S}$

where $\varepsilon$ is the basal emission rate $\left(\mu \mathrm{g} \mathrm{C} \mathrm{g}{ }^{-1} \mathrm{~h}^{-1}\right)$ at standard conditions (i.e. $30{ }^{\circ} \mathrm{C}$ leaf temperature and $1000 \mu \mathrm{mol} \mathrm{m}{ }^{-2} \mathrm{~s}^{-1}$ photosynthetically active radiation (PAR)); $D$ is the peak foliar mass (g); $\gamma_{T}, \gamma_{P}$, and $\gamma_{S}$ are environmental correction factors accounting for the influence of temperature, light intensity, and seasonal variation on synthesis emissions; and $\gamma_{C}$ is the $\mathrm{CO}_{2}$ inhibition on isoprene emission.

The basal emission rates $(\varepsilon)$ of isoprene (Table A.2), monoterpenes (Table A.3), OVOCs (Table A.4), and the light dependent fraction (Table A.5) of monoterpenes were collected from published literatures (e.g. Klinger et al., 2002; Ren et al., 2014) and were assigned to each tree species using a taxonomic approach (Benjamin et al., 1996).

We used allometric equations (Table A.6) related to DBH to calculate the peak leaf biomass $(D)$ of each tree species. To calculate the environmental correction factors, hourly air temperature and PAR data obtained from the meteorological data center of the China Meteorological Administration and monthly $\mathrm{CO}_{2}$ concentration data from the Shangdianzi Baseline Observatory were used. As light varies dramatically within a tree canopy resulting in much lower emissions, a simple canopy model was applied to simulate the effects of solar radiation extinction (Geron et al., 1994).

The pool monoterpenes $\left(E_{M N P}\right)$ and OVOCs $\left(E_{O V P}\right)$ emissions were quantified as:

$E_{M N P}=\varepsilon_{M N P} D \gamma_{T} \gamma_{S}$

$E_{O V P}=\varepsilon_{O V P} D \gamma_{T} \gamma_{S}$

where $D, \gamma_{T}$, and $\gamma_{P}$ have the same meaning as those in Eq. (3). The details and calculations of $D, \gamma_{T}, \gamma_{P}, \gamma_{G} \gamma_{S}$ and the canopy model are found in the Appendix. The details and calculations of $D, \gamma_{T}, \gamma_{P}, \gamma_{G} \gamma_{S}$ and the canopy model are found in the Appendix. BVOC emissions from urban areas may also be influenced by some abiotic or biotic stresses (Peñuelas and Staudt, 2010; Ghirardo et al., 2016). Analyzing plant responses and adaptations to multiple stressors, defined as 'urban plant physiology' (Calfapietra et al., 2015), could achieve more accurate estimations on urban BVOC emissions. However, due to the lack of knowledge on these "stress-induced" emissions (Oderbolz et al., 2013), this study is limited to stress-free conditions.

We applied a dynamic BVOC estimation model (Ren et al., 2014) to further investigate the temporal trends of BVOC emissions and the role of management strategies in mitigating those emissions. The model included two parts. Part 1 was used to simulate processes like green space expansion, the tree planting/replacement, and tree growth with a temporal resolution of one year (Fig. A.1). The input of part 1 included the areal extent, species composition, tree density and age distribution of urban green spaces, and the peak leaf biomass of individual trees in each age group for each tree species. The output of part 1 was the peak leaf biomass of each tree species in each simulation year. Part 2 used species-specific basal emission rates, hourly meteorological data (temperature, $\mathrm{PAR}$ ), $\mathrm{CO}_{2}$ concentration data and the output of part 1 as its inputs and used the algorithms outlined above to simulate the hourly BVOC emissions for each tree species in each year (Fig. A.2). The time step and temporal resolution of part 2 was $1 \mathrm{~h}$.

\subsection{Scenario analysis}

We developed a series of scenarios to explore the effects of tree species introduction on future plant biodiversity and BVOC emissions. In the business-as-usual (BAU) scenario, the annual air temperature of Qingdao in 2050 is projected to be $1.96{ }^{\circ} \mathrm{C}$ higher than present under the medium-mitigation emission scenario RCP 4.5 (Sun et al., 2015); the variations of $\mathrm{CO}_{2}$ concentration $\left(+3.5 \mathrm{ppm} \mathrm{yr}^{-1}\right.$ ) (Fang et al., 2014) and urban green space expansion (+1250 ha $\mathrm{yr}^{-1}$ ) (NBSC, 2016) in Qingdao were assumed to follow current trends. Species composition of urban green spaces was assumed to remain unchanged over time since 2014. The annual increments of DBH (Table A.7) of different tree species were collected to simulate the changes in foliar mass during tree growth.

We then designed three urban green space management scenarios. In this study, we defined a tree species as a high-emitting species if the sum of its isoprene and monoterpene basal emission rates exceeded $10 \mu \mathrm{g}$ of $\mathrm{C} \mathrm{g}^{-1} \mathrm{~h}^{-1}$; if the sum is less than $10 \mu \mathrm{g}$ of $\mathrm{C} \mathrm{g}^{-1} \mathrm{~h}^{-1}$ and higher than $1 \mu \mathrm{g}$ of $\mathrm{C} \mathrm{g}^{-1} \mathrm{~h}^{-1}$, the species was defined as middleemitting species; otherwise it is a low-emitting species (Ren et al., 2014). In the 'proactive introduction' scenario, the species composition of newly planted trees and existing trees was optimized through a moderate introduction of low-emitting ornamental tree species, that is, change the high-emitting species to combinations of the 11 selected ornamental species gradually. By 2050, the target proportion of these introduced species in total number of tree individuals was $15 \%$. Under the 'local optimization' scenario, the high-emitting species will be replaced by the low-emitting species that have been used in the urban greening of Qingdao. The same target proportion of $15 \%$ was set to make it comparable to the 'proactive introduction' scenario. In the "reckless promotion" scenario, urban greening will continue to expand the use of the high-emitting introduced species, while reducing the use of the low-emitting local species. The proportion of the high-emitting introduced species was assumed to increase $15 \%$ by 2050 .

\section{Results}

\subsection{Species composition and plant diversity of green spaces in Qingdao City}

In the urban vegetation survey of Qingdao, a total of 72 tree species were recorded (Table 1; Table A.1). These species belonged to 52 genera and 20 families. Among tree species, there were 60 deciduous species and 12 evergreen species. All deciduous species were broadleaved trees and accounted for $76.5 \%$ of the total number of tree individuals; most evergreen species were conifers, such as pine and cypress, accounting for $22.2 \%$ of the total number of tree individuals; only two evergreen broad-leaved tree species, Magnolia grandiflora and $\mathrm{Li}$ gustrum lucidum, were founded in the survey. Park green space had the 
Table 3

Comparison of tree species diversity and phylogenetic diversity of urban green spaces in other cities.

\begin{tabular}{lllll}
\hline City & Key attribute & Gleason $^{\mathrm{a}}$ & Phylogenetic & Sources \\
\hline Qingdao (urban) & Mean & 0.75 & 42 & This study \\
& Max & 1.67 & 89 & \\
& Min & 0.17 & 18 & \\
& Overall & 3.75 & 280 & Cao (2015) \\
Qingdao (rural) & Overall & 4.82 & 326 & Ren et al., (2017) \\
Beijing & Overall & 4.17 & 305 & Zhang et al. (2016) \\
Changchun & Overall & 3.49 & $\mathrm{NM}^{\mathrm{b}}$ & Yang (2015) \\
Nanjing & Overall & 4.58 & $\mathrm{NM}^{\mathrm{b}}$ & Chang et al. (2012) \\
Hangzhou & Overall & 5.06 & 392 & Jim and Liu (2001) \\
Guangzhou & Overall & 12.97 & $\mathrm{NM}^{\mathrm{b}}$ & \\
\hline
\end{tabular}

a The Gleason index was calculated using the species richness reported in the literature and the areal extent of green spaces in the corresponding city.

${ }^{\mathrm{b}} \mathrm{NM}$ : not mentioned.

highest species richness with 63 species, followed by affiliated, residential, and street green spaces with 51,46 , and 38 species, respectively. There were 33 exotic tree species, accounting for $62 \%$ of total number of tree individuals (Table A.1).

The average DBH and tree height were $18.4 \mathrm{~cm}$ and $8.3 \mathrm{~m}$, respectively. Platanus acerifolia, Pinus thunbergii and Cedrus deodara were widely used in all types of green space and had the highest relative abundance and important value. Cedrus deodara, Robinia pseudoacacia, Sophora japonica, Ginkgo biloba, and Albizia julibrissin also had relatively high important values (Table 1 ).

In 2014, the average site-level and the overall (i.e. the value of the whole city) Gleason index of urban green spaces in Qingdao were 0.75 and 3.75, respectively. The overall phylogenetic diversity of green spaces was 280 (Table 3; Fig. 1). Under the BAU scenario, as we assume no new tree species are introduced, and urban green spaces are expanding in area, the overall Gleason index decreases year by year and decreases to 3.65 by 2050, while the overall phylogenetic diversity remains unchanged during this period.

\subsection{Adaptability of introduced tree species}

In the introduction trial, the deciduous broad-leaved species Houpoea officinalis had the highest survival rate (98\%), followed by the two evergreen deciduous broad-leaved species Michelia chapensis and Ilex rubra. Only Cercidiphyllum japonicum and Nyssa sinensis had survival rates lower than $90 \%$ (Table 2). Most tree deaths happened in the year 2015 when there was the coldest winter in the past 30 years. The evergreen broad-leaved species Ilex rubra had the highest annual DBH increment of $0.87 \mathrm{~cm} \mathrm{yr}^{-1}$. For other species, DBH increments ranged from 0.35 to $0.82 \mathrm{~cm} \mathrm{yr}^{-1}$ (Table 2). Considering their BVOC emissions and adaptability to the urban environment, we recommended 11 of the 13 ornamental tree species to be promoted in the urban greening of Qingdao City (Table 2; Fig. 1). Their average mortality rate was similar to that (94\%) of commonly used tree species in Qingdao.

\subsection{BVOC emissions from different tree species}

As shown in Fig. 2, many common tree species in the urban green spaces of Qingdao are strong BVOC emitters. Among the primary tree species, $P$. tomentosa possessed the highest individual BVOC emission potential (1313 g C tree ${ }^{-1}$ ), followed by Platycladus orientalis (1047 g C tree ${ }^{-1}$ ), Salix babylonica $\left(472 \mathrm{~g} \mathrm{C}^{-1} \mathrm{tre}^{-1}\right.$ ) and Populus $\times$ canadensis $\left(417 \mathrm{~g} \mathrm{C}\right.$ tree $\left.^{-1}\right)$. P. acerifolia, Liquidambar formosana, $M$. grandiflora and $S$. japonica also exhibited relatively high emission potentials (Fig. 2).

The total BVOC emissions from urban green spaces in Qingdao were dominated by only a few tree species despite the fact that dozens of tree species were planted. P. acerifolia, $P$. tomentosa, S. japonica, $P$. orientalis and $P$. thunbergii contributed the most to the total urban BVOC emissions. These 5 tree species accounted for $36 \%$ of the total number of tree individuals, while contributing $78 \%$ of total urban BVOC emissions. Among the top 20 tree species with the highest individual BVOC emission potentials, 11 species were introduced species (Fig. 2; Table A.1).

\subsection{Temporal trends of total BVOC emissions and emission intensity}

In 2014, the annual BVOC emission from urban green spaces was $1.27 \times 10^{9} \mathrm{~g} \mathrm{C} \mathrm{yr}^{-1}$; isoprene, monoterpenes, and OVOCs contributed 65,17 , and 18\%, respectively (Fig. 3).The vegetation-based BVOC emission intensity (defined as BVOC emissions per unit land area occupied by vegetation) of Qingdao was $5.8 \mathrm{~g} \mathrm{C} \mathrm{m}^{-2} \mathrm{yr}^{-1}$, and the region-based emission intensity (BVOC emissions per unit built-up area) was $2.6 \mathrm{~g} \mathrm{C} \mathrm{m}^{-2} \mathrm{yr}^{-1}$.

Along with environmental changes and the further expansion of urban green spaces (BAU scenario), the BVOC emissions from urban green spaces were projected to rise rapidly and will reach $4.1 \times 10^{9} \mathrm{~g} \mathrm{C}$ $\mathrm{yr}^{-1}$ by 2050 (Fig. 3), increasing by $222 \%$ compared with emissions in 2014. This increase mostly resulted from the rapid growth of urban trees and the planting of new trees. As isoprene emissions were lightdependent and inhibited by a high atmospheric $\mathrm{CO}_{2}$ concentration, its emissions increase initially then begin to decrease around 2045. As some monoterpenes and all OVOCs emissions were light-independent, both of their emissions continued increasing year by year (Fig. 3). In 2050 , the combined contribution of monoterpenes (29\%) and OVOCs (24\%) exceed that of isoprene (47\%).The vegetation-based and regionbased emission intensity will also increase to $11.1 \mathrm{~g} \mathrm{C} \mathrm{m}^{-2} \mathrm{yr}^{-1}$ and $4.9 \mathrm{~g} \mathrm{C} \mathrm{m}^{-2} \mathrm{yr}^{-1}$ by 2050 , respectively.

\section{Discussion}

\subsection{Significance of introduced species to enhance plant diversity of green spaces}

Preserving biodiversity should be an important goal of strategic urban green space planning and management, especially in highly urbanized areas where little natural habitat remains (Kenney et al., 2011). Compared with other Chinese cities, the species diversity (Gleason index) of green spaces in Qingdao was comparable to Beijing and Changchun (Zhang et al., 2016) in northern China, while being lower than Nanjing (Yang, 2015), Hangzhou (Chang et al., 2012) and Guangzhou (Jim and Liu, 2001) in southern China (Table 3). In addition, urban species diversity was also $22 \%$ lower than the surrounding rural forests of Qingdao (Cao, 2015).

As for phylogenetic diversity (PD), Qingdao had the lowest value compared to other cities and the rural forests surrounding Qingdao (Table 3). The diminished phylogenetic information might decrease the capacity of urban green spaces to respond to environmental changes (Knapp et al., 2008). There is an urgent need to increase the species diversity and phylogenetic diversity of urbanized Qingdao.

Through the introduction of 11 selected ornamental tree species, the plant diversity of green spaces improved significantly. By 2050, the Gleason index of the whole city increased to 4.21 , and the phylogenetic diversity increased to 315 . These improvements in plant diversity are crucial for urban green spaces to sustain their various ecosystem functioning and sustainably supply the ecosystem services. Plant diversity was often used as a proxy for cultural services (Graves et al., 2017), meaning that the introduction of the ornamental tree species could contribute significantly to the enhancement of cultural services in urban areas. Moreover, since about half of the selected tree species are listed as national key protected wild plants (Table 2), the introduction and promotion is helpful for the ex situ conservation of these valuable plant species in cities. 

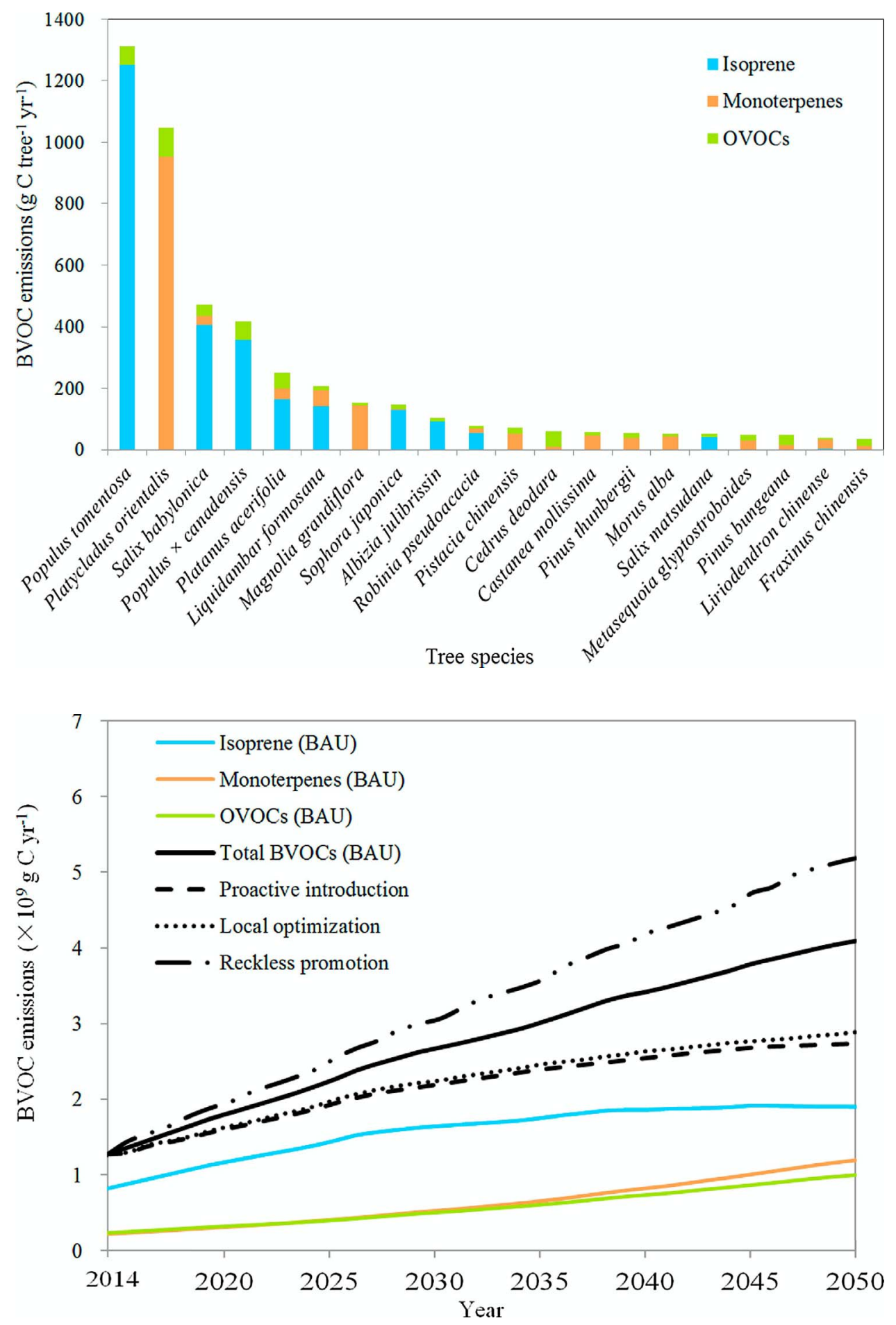

Fig. 2. The average individual BVOC emission potentials of the primary tree species in green spaces of Qingdao in 2014. (For interpretation of the references to colour in this figure legend, the reader is referred to the web version of this article.)
Fig. 3. Time series of annual BVOC emissions from urban green spaces in Qingdao under the BAU scenario and various management scenarios. (For interpretation of the references to colour in this figure legend, the reader is referred to the web version of this article.)

\subsection{Significance of introduced species to mitigating urban BVOC emissions}

At present, Qingdao had moderate total BVOC emissions and emission intensity compared with other cities (Table 4) (Guo et al., 2013; Ren et al., 2014; Ghirardo et al., 2016). But compared with the background emissions of Shandong Province (2.1 $\mathrm{g} \mathrm{C} \mathrm{m}^{-2} \mathrm{yr}-1$ ) (Fu and Liao, 2012), the built-up areas of Qingdao are hotspots of regional BVOC emissions. BVOCs mainly have local or regional air quality and human health impacts owing to their high chemical reactivity in the atmosphere (Harrison et al., 2013). Considering that more than $68 \%$ of Qingdao's population lives in the built-up areas (QBS, 2015), Qingdao is facing a challenging situation to control its urban BVOC emissions. In
China, short-term and long-term measures to mitigate AVOCs have been implemented to reduce ozone and $\mathrm{PM}_{2.5}$ pollutions in urban areas (Wang et al., 2015) but if the high BVOC emissions are not considered, the success of the current efforts to mitigate air pollution will be compromised (Simpson and McPherson, 2011).

By 2050, through a moderate introduction of the 11 selected lowemitting tree species to green spaces ('proactive introduction' scenario), the total BVOC emissions could be reduced by $34 \%$ compared with the BAU scenario (Fig. 3). These reductions in BVOC emissions will play significant roles in improving human health conditions in Qingdao. 
Table 4

Estimates of BVOC emissions from different urban regions and in combination with a comparison to China and the planet as a whole.

\begin{tabular}{|c|c|c|c|c|}
\hline Region & Area $\left(\times 10^{3} \mathrm{~km}^{2}\right)$ & BVOC emissions $\left(\times 10^{9} \mathrm{~g} \mathrm{C} \mathrm{yr}^{-1}\right)$ & Emission intensity $\left(\mathrm{g} \mathrm{C} \mathrm{m}^{-2}\right)$ & Sources \\
\hline Qingdao & $0.5^{\mathrm{a}}$ & 1.3 & 2.6 & This study \\
\hline Hangzhou & $0.4^{\mathrm{a}}$ & 0.5 & 1.1 & Ren et al. (2014) \\
\hline Ningbo & $0.3^{\mathrm{a}}$ & 0.4 & 1.5 & Guo et al. (2013) \\
\hline Beijing & $1.2^{\mathrm{a}}$ & 10.3 & 8.6 & Ghirardo et al. (2016) \\
\hline Hong Kong & 1.1 & 9 & 7.8 & Tsui et al. (2009) \\
\hline Las Vegas & 0.8 & 3.4 & 4.0 & Papiez et al. (2009) \\
\hline China & $9.6 \times 10^{3}$ & 18.7 & 1.9 & Fu and Liao, (2012) \\
\hline Planet (land) & $147 \times 10^{3}$ & $1.0 \times 10^{6}$ & 6.8 & Guenther et al. (2012) \\
\hline
\end{tabular}

${ }^{\mathrm{a}}$ Urban built-up area.

\subsection{A win-win strategy for urban green space management}

Decision making should be based upon a trade-off between the ecosystem service costs and benefits of urban green spaces (Escobedo et al., 2011; Pataki et al., 2011). In the 'proactive introduction' scenario, a moderate introduction of ornamental tree species was not only good for biodiversity conservation but also reduced the BVOC emissions of urban green spaces. Though the 'local optimization' scenario had similar effects on mitigating BVOC emissions (Fig. 3), it did not improve the biodiversity of urban green spaces. The 'reckless promotion' scenario was the worst choice; it did not enhance biodiversity but would increase urban BVOC emissions by $27 \%$ (Fig. 3). These results highlighted the importance of selecting the appropriate trees species in the context of rapid urbanization and the inevitable trend of species introduction.

In the current practice of urban greening, most of the introduced plants have been selected for their ornamental traits and their ability to thrive in urban green spaces. We suggest that their effects on biodiversity and BVOC emissions should also be considered in landscape planning to achieve proactive management. Ideally, more effects, such as provisioning and regulating ecosystem services, should be included in urban tree selection to maximize their benefits while minimizing the negative effects.

Global warming, urban heat island effects and improvements in gardening practices have resulted in the reduction of most environmental stresses that introduced plants must tolerate (Niinemets and Peñuelas, 2008), making it easier to grow introduced tree species that originate from warmer regions in cooler cities. The scheme of introducing low-emitting species leads to a win-win situation and also has implications for the green space management of other cities located in the temperate zone. Given the current trend of biotic homogenization (Qian et al., 2016), measures that introduce and acclimatize native species with low BVOC emissions and good ornamental values to urban green spaces should also be emphasized.

\subsection{Uncertainty analysis}

A series of Monte Carlo simulations (10,000 runs) were conducted to characterize the uncertainties associated with our BVOC estimates (Table A.8). The median and 95\% confidence intervals were calculated and used to represent the uncertainties. Based on the Monte Carlo analysis, the uncertainties associated with our BVOC estimates were between $-49 \%$ and $47 \%$ in 2014 . Uncertainties related to the basal emission rates, model algorithms, empirical coefficients, and leaf biomass equations (Table A.8) were all important uncertainty sources of our estimates on BVOC emissions (Chang et al., 2012).

Besides the uncertainty sources considered in the Monte Carlo analysis, there are still some assumptions used in this study that may affect our estimates. Given the growing evidence that urban trees may have high stress-induced BVOC emissions when suffering environmental stresses (Peñuelas and Staudt, 2010; Mentel et al., 2013), our "stress-free" assumption could result in an underestimation of BVOC emissions (Ghirardo et al., 2016). To evaluate the relative contribution of stress-induced emissions, we conducted a sensitive analysis by using the latest species-specific induced monoterpenes emission rates from Ghirardo et al. (2016) to rerun the model. Results showed that our new estimate of monoterpenes emissions in 2014 was $17 \%$ higher than previous estimate after considering stress-induced emissions. We used air temperature instead of leaf temperature to calculate the temperature correction factor as the latter was not available, which would also lead to an underestimation of BVOC emissions, especially for broad-leaved trees (Leuzinger and Koerner, 2007). Moreover, we only considered the biochemical down-regulation of the isoprene synthesis under elevated $\mathrm{CO}_{2}$ concentrations (Heald et al., 2009). While in fact, the inhibition effect can be largely compensated by the stimulated growth of the canopy leaf under higher $\mathrm{CO}_{2}$ concentrations (Sun et al., 2013; Vanzo et al., 2015). Given the many uncertainties related to the empirical models, data sources and the assumptions, the lack of validation is a limitation of this study that should be addressed by future research.

\section{Conclusions}

In this study, based on detailed investigations of urban green spaces and an urban BVOC estimation model, the trade-off between biodiversity preservation and BVOC emissions of urban green spaces was evaluated for the first time. As a proxy of many ecosystem services, plant diversity in green spaces in Qingdao City was lower than their rural surroundings. However, urban areas have become hotspots of regional BVOC emissions, partly due to the reckless introduction of ornamental tree species. Furthermore, if no effective measures are taken, urban BVOC emissions in Qingdao will more than triple by 2050, which will have significant effects on future urban air quality and ultimately human health.

Our study highlights the importance of introducing the appropriate trees species to maximize the net benefits of urban green spaces. Through a moderate $(15 \%)$ introduction of 11 low-emitting ornamental tree species that have good adaptability to the urban environment of Qingdao, the species diversity and phylogenetic diversity of green spaces will increase by $15 \%$ and $11 \%$, respectively. At the same time, one third of BVOC emissions can be reduced by 2050. This is a win-win strategy for urban green space management to increase co-benefits between biodiversity preservation and BVOC reduction, and thus can be applied to landscape planning in other cities. Although uncertainties exist within the present study, we believe our work is an important step to achieving a better understanding and effective management of urban green spaces.

\section{Acknowledgements}

This work was financially supported by the National Natural Science Foundation of China (31370354, 31270377, and 31400607). We thank H. Xue, P. Ma, F. Zhang, and Y. Liu for their field and lab work, and comments on an earlier version of the manuscript. 


\section{Appendix A. Supplementary data}

Supplementary data associated with this article can be found, in the online version, at http://dx.doi.org/10.1016/j.ufug.2017.08.011.

\section{References}

APG III. (Angiosperm Phylogeny Group III), 2009. An update of the Angiosperm Phylogeny Group classification for the orders and families of flowering plants: APG III. Bot. J. Linn. Soc. 161, 105-121.

Aydin, Y.M., Yaman, B., Koca, H., Dasdemir, O., Kara, M., Altiok, H., Dumanoglu, Y., Bayram, A., Tolunay, D., Odabasi, M., Elbir, T., 2014. Biogenic volatile organic compound (BVOC) emissions from forested areas in Turkey: determination of specific emission rates for thirty-one tree species. Sci. Total Environ. 490, 239-253.

Benjamin, M.T., Sudol, M., Bloch, L., Winer, A.M., 1996. Low-emitting urban forests: a taxonomic methodology for assigning isoprene and monoterpene emission rates. Atmos. Environ. 30 (9), 1437-1452.

Calfapietra, C., Fares, S., Manes, F., Morani, A., Sgrigna, G., Loreto, F., 2013. Role of Biogenic Volatile Organic Compounds (BVOC) emitted by urban trees on ozone concentration in cities: a review. Environ. Pollut. 183, 71-80.

Calfapietra, C., Penuelas, J., Niinemets, U., 2015. Urban plant physiology: adaptationmitigation strategies under permanent stress. Trends Plant Sci. 20 (2), 72-75.

Cao, Y.Q., 2015. Flora of Qingdao. China Forestry Publishing House, Beijing (in Chinese).

Chang, J., Ren, Y., Shi, Y., Zhu, Y., Ge, Y., Hong, S., Jiao, L., Lin, F., Peng, C., Mochizuki, T., Tani, A., Mu, Y., Fu, C., 2012. An inventory of biogenic volatile organic compounds for a subtropical urban-rural complex. Atmos. Environ. 56, 115-123.

Escobedo, F.J., Kroeger, T., Wagner, J.E., 2011. Urban forests and pollution mitigation: analyzing ecosystem services and disservices. Environ. Pollut. 159 (8-9), 2078-2087.

Faith, D.P., 1992. Conservation evaluation and phylogenetic diversity. Biol. Conserv. 61 (1), $1-10$.

Fang, S.X., Zhou, L.X., Tans, P.P., Ciais, P., Steinbacher, M., Xu, L., Luan, T., 2014. In situ measurement of atmospheric $\mathrm{CO} 2$ at the four WMO/GAW stations in China. Atmos. Chem. Phys. 14 (5), 2541-2554.

$\mathrm{Fu}$, Y., Liao, H., 2012. Simulation of the interannual variations of biogenic emissions of volatile organic compounds in China: impacts on tropospheric ozone and secondary organic aerosol. Atmos. Environ. 59, 170-185.

Geron, C.D., Guenther, A.B., Pierce, T.E., 1994. An improved model for estimating emissions of volatile organic compounds from forests in the eastern United States. J. Geophys. Res-Atmos. 99 (D6), 12773-12791.

Ghirardo, A., Koch, K., Taipale, R., Zimmer, I., Schnitzler, J.-P., Rinne, J., 2010. Determination of de novo and pool emissions of terpenes from four common boreal/ alpine trees by $13 \mathrm{CO}(2)$ labelling and PTR-MS analysis. Plant Cell Environ. 33 (5), 781-792.

Ghirardo, A., Xie, J.F., Zheng, X.H., Wang, Y.S., Grote, R., Block, K., Wildt, J., Mentel, T., Kiendler-Scharr, A., Hallquist, M., Butterbach-Bahl, K., Schnitzler, J.P., 2016. Urban stress-induced biogenic VOC emissions and SOA-forming potentials in Beijing. Atmos. Chem. Phys. 16 (5), 2901-2920.

Gleason, H.A., 1922. On the relation between species and area. Ecology 3, 158-162.

Goddard, M.A., Dougill, A.J., Benton, T.G., 2010. Scaling up from gardens: biodiversity conservation in urban environments. Trends Ecol. Evol. 25 (2), 90-98.

Graves, R.A., Pearson, S.M., Turner, M.G., 2017. Species richness alone does not predict cultural ecosystem service value. Proc. Natl. Acad. Sci. U. S. A. 114 (14), 3774-3779.

Guenther, A., Hewitt, C.N., Erickson, D., Fall, R., Geron, C., Graedel, T., Harley, P., Klinger, L., Lerdau, M., McKay, W.A., Pierce, T., Scholes, B., Steinbrecher, R., Tallamraju, R., Taylor, J., Zimmerman, P., 1995. A global model of natural volatile organic compound emissions. J. Geophys. Res. 100 (D5), 8873-8892.

Guenther, A.B., Jiang, X., Heald, C.L., Sakulyanontvittaya, T., Duhl, T., Emmons, L.K., Wang, X., 2012. The Model of Emissions of Gases and Aerosols from Nature version 2.1 (MEGAN2.1): an extended and updated framework for modeling biogenic emissions. Geosci. Model Dev. 5 (6), 1471-1492.

Guenther, A., 1997. Seasonal and spatial variations in natural volatile organic compound emissions. Ecol. Appl. 7 (1), 34-45.

Guo, P., Guo, K., Ren, Y., Shi, Y., Chang, J., Tani, A., Ge, Y., 2013. Biogenic volatile organic compound emissions in relation to plant carbon fixation in a subtropical urban-rural complex. Landsc. Urban Plan. 119, 74-84.

Harrison, S.P., Morfopoulos, C., Dani, K.G.S., Prentice, I.C., Arneth, A., Atwell, B.J., Barkley, M.P., Leishman, M.R., Loreto, F., Medlyn, B.E., Niinemets, U., Possell, M., Penuelas, J., Wright, I.J., 2013. Volatile isoprenoid emissions from plastid to planet. New Phytol. 197 (1), 49-57.

Heald, C.L., Wilkinson, M.J., Monson, R.K., Alo, C.A., Wang, G., Guenther, A., 2009. Response of isoprene emission to ambient $\mathrm{CO} 2$ changes and implications for global budgets. Glob. Change Biol. 15 (5), 1127-1140.

Jim, C.Y., Liu, H.T., 2001. Species diversity of three major urban forest types in Guangzhou City, China. For. Ecol. Manage. 146 (1-3), 99-114.

Kenney, W.A., van Wassenaer, P.J.E., Satel, A.L., 2011. Criteria and indicators for strategic urban forest planning and management. Arboriculture Urban For. 37 (3), 108-117.

Klinger, L.F., Li, Q.J., Guenther, A.B., Greenberg, J.P., Baker, B., Bai, J.H., 2002. Assessment of volatile organic compound emissions from ecosystems of China. J. Geophys. Res-Atmos. 107 (D21).

Knapp, S., Kuehn, I., Schweiger, O., Klotz, S., 2008. Challenging urban species diversity: contrasting phylogenetic patterns across plant functional groups in Germany. Ecol. Lett. 11 (10), 1054-1064.

Kowarik, I., 2011. Novel urban ecosystems, biodiversity, and conservation. Environ.
Pollut. 159 (8-9), 1974-1983.

Letunic, I., Bork, P., 2006. Interactive Tree Of Life (iTOL): an online tool for phylogenetic tree display and annotation. Bioinformatics 23, 127-128. http://dx.doi.org/10.1093/ bioinformatics/btl529.

Leuzinger, S., Koerner, C., 2007. Tree species diversity affects canopy leaf temperatures in a mature temperate forest. Agric. Forest Meteorol. 146 (1-2), 29-37.

Mentel, T.F., Kleist, E., Andres, S., Dal Maso, M., Hohaus, T., Kiendler-Scharr, A., Rudich, Y., Springer, M., Tillmann, R., Uerlings, R., Wahner, A., Wildt, J., 2013. Secondary aerosol formation from stress-induced biogenic emissions and possible climate feedbacks. Atmos. Chem. Phys. 13 (17), 8755-8770.

Mueller, S.F., Mallard, J.W., 2011. Contributions of natural emissions to ozone and PM2.5 as simulated by the community multiscale air quality (CMAQ) model. Environ. Sci Technol. 45 (11), 4817-4823.

NBSC (National Bureau of Statistics of China), 2016. China City Statistical Yearbook. China Statistics Press, Beijing 2001 (in Chinese).

Nielsen, A.B., van den Bosch, M., Maruthaveeran, S., van den Bosch, C.K., 2014. Species richness in urban parks and its drivers: a review of empirical evidence. Urban Ecosyst. 17 (1), 305-327.

Niinemets, U., Peñuelas, J., 2008. Gardening and urban landscaping: significant players in global change. Trends Plant Sci. 13 (2), 60-65.

Noe, S.M., Penuelas, J., Niinemets, U., 2008. Monoterpene emissions from ornamental trees in urban areas: a case study of Barcelona, Spain. Plant Biol. 10 (1), 163-169.

Nowak, D.J., Walton, J.T., Stevens, J.C., Crane, D.E., Hoehn, R.E., 2008. Effect of plot and sample size on timing and precision of urban forest assessments. arboriculture. Urban For. 34 (6), 386-390.

Oderbolz, D.C., Aksoyoglu, S., Keller, J., Barmpadimos, I., Steinbrecher, R., Skjoth, C.A., Plass-Duelmer, C., Prevot, A.S.H., 2013. A comprehensive emission inventory of biogenic volatile organic compounds in Europe: improved seasonality and landcover. Atmos. Chem. Phys. 13 (4), 1689-1712.

Palliwoda, J., Kowarik, I., von der Lippe, M., 2017. Human-biodiversity interactions in urban parks: the species level matters. Landsc. Urban Plan. 157, 394-406.

Papiez, M.R., Potosnak, M.J., Goliff, W.S., Guenther, A.B., Matsunaga, S.N., Stockwell, W.R., 2009. The impacts of reactive terpene emissions from plants on air quality in Las Vegas, Nevada. Atmos. Environ. 43 (27), 4109-4123.

Pataki, D.E., Carreiro, M.M., Cherrier, J., Grulke, N.E., Jennings, V., Pincetl, S., Pouyat, R.V., Whitlow, T.H., Zipperer, W.C., 2011. Coupling biogeochemical cycles in urban environments: ecosystem services, green solutions, and misconceptions. Front. Ecol. Environ. 9 (1), 27-36.

Peñuelas, J., Staudt, M., 2010. BVOCs and global change. Trends Plant Sci. 15 (3), 133-144.

QBS (Qingdao Bureau of Statistics), 2015. Qingdao Statistical Yearbook. China Statistics Press, Beijing (in Chinese).

Qian, S., Qi, M., Huang, L., Zhao, L., Lin, D., Yang, Y., 2016. Biotic homogenization of China's urban greening: a meta-analysis on woody species. Urban For. Urban Green. $18,25-33$.

Ramalho, C.E., Hobbs, R.J., 2012. Time for a change: dynamic urban ecology. Trends Ecol. Evol. 27 (3), 179-188.

Ren, Y., Ge, Y., Gu, B.J., Min, Y., Tani, A., Chang, J., 2014. Role of management strategies and environmental factors in determining the emissions of biogenic volatile organic compounds from urban greenspaces. Environ. Sci. Technol. 48 (11), 6237-6246.

Ren, Y., Qu, Z.L., Du, Y.Y., Xu, R.H., Ma, D.P., Yang, G.F., Shi, Y., Fan, X., Tani, A., Guo, P.P., Ge, Y., Chang, J., 2017. Air quality and health effects of biogenic volatile organic compounds emissions from urban green spaces and the mitigation strategies. Environ. Pollut. 230, 849-861.

Seto, K.C., Gueneralp, B., Hutyra, L.R., 2012. Global forecasts of urban expansion to 2030 and direct impacts on biodiversity and carbon pools. Proc. Natl. Acad. Sci. U. S. A. 109 (40), 16083-16088.

Simpson, J.R., McPherson, E.G., 2011. The tree BVOC index. Environ. Pollut. 159 (8-9), 2088-2093.

Staudt, M., Bertin, N., Frenzel, B., Seufert, G., 2000. Seasonal variation in amount and composition of monoterpenes emitted by young Pinus pinea Trees - Implications for emission modeling. J. Atmos. Chem. 35 (1), 77-99.

Sun, Z., Niinemets, U., Hueve, K., Rasulov, B., Noe, S.M., 2013. Elevated atmospheric CO2 concentration leads to increased whole-plant isoprene emission in hybrid aspen (Populus tremula x Populus tremuloides). New Phytol. 198 (3), 788-800.

Sun, Q., Miao, C., Duan, Q., 2015. Projected changes in temperature and precipitation in ten river basins over China in 21 st century. Int. J. Climatol. 35 (6), 1125-1141.

Tani, A., Kawawata, Y., 2008. Isoprene emission from the major native Quercus spp in Japan. Atmos. Environ. 42 (19), 4540-4550.

Tiwary, A., Kumar, P., 2014. Impact evaluation of green-grey infrastructure interaction on built-space integrity: an emerging perspective to urban ecosystem service. Sci. Total Environ. 487, 350-360.

Tsui, J.K.-Y., Guenther, A., Yip, W.-K., Chen, F., 2009. A biogenic volatile organic compound emission inventory for Hong Kong. Atmos. Environ. 43 (40), 6442-6448.

Vanzo, E., Jud, W., Li, Z., Albert, A., Domagalska, M.A., Ghirardo, A., Niederbacher, B., Frenzel, J., Beemster, G.T.S., Asard, H., Rennenberg, H., Sharkey, T.D., Hansel, A., Schnitzler, J.-P., 2015. Facing the future: effects of short-Term climate extremes on isoprene-Emitting and nonemitting poplar. Plant Physiol. 169 (1), 560.

Wang, M., Shao, M., Chen, W., Lu, S., Liu, Y., Yuan, B., Zhang, Q., Chang, C.C., Wang, B., Zeng, L., Hu, M., Yang, Y., Li, Y., 2015. Trends of non-methane hydrocarbons (NMHC) emissions in Beijing during 2002-2013. Atmos. Chem. Phys. 15 (3), 1489-1502.

Webb, C.O., Donoghue, M.J., 2005. Phylomatic: tree assembly for applied phylogenetics. Mol. Ecol. Notes 5, 181-183.

Webb, C.O., Ackerly, D.D., Kembel, S.W., 2008. Phylocom: Software for the Analysis of Phylogenetic Community Structure and Character Evolution Version 4.0.1. (URL:). 
http://phylodiversity.net/phylocom/.

Wikstrom, N., Savolainen, V., Chase, M.W., 2001. Evolution of the angiosperms: calibrating the family tree. Proc. R. Soc. B-Biol. Sci. 268 (1482), 2211-2220.

Wolch, J.R., Byrne, J., Newell, J.P., 2014. Urban green space, public health, and environmental justice: the challenge of making cities 'just green enough'. Landsc. Urban Plan. 125, 234-244.

Yang, J., 2015. Study on the Diversity of Woody Plant Communities in Green Spaces of
Nanjing City. Master Dissertation. Nanjing Agricultural University, Nanjing, Jiangsu (in Chinese).

Zhang, H., Jim, C.Y., 2014. Species diversity and performance assessment of trees in domestic gardens. Landsc. Urban Plan. 128, 23-34.

Zhang, D., Zheng, H.F., He, X.Y., Ren, Z.B., Zhai, C., Yu, X.Y., Mao, Z.X., Wang, P.J., 2016. Effects of forest type and urbanization on species composition and diversity of urban forest in Changchun, Northeast China. Urban Ecosyst. 19 (1), 455-473. 